\title{
A new photosensory function for simple photoreceptors, the intrinsically photoresponsive neurons of the sea slug Onchidium
}

\author{
Tsukasa Gotow ${ }^{1 *}$ and Takako Nishi ${ }^{2}$ \\ Laboratory for Neuroanatomy, Department of Neurology, Graduate School of Medical and Dental Sciences, Kagoshima University, Kagoshima, Japan \\ 2 Laboratory of Physiology, Institute of Natural Sciences, Senshu University, Kawasaki, Japan
}

\section{Edited by:}

Dieter Wicher, Max Planck Institute for

Chemical Ecology, Germany

Reviewed by:

Christian Derst, Institut für Integrative Neuroanatomie der Charité, Germany Ulf Bickmeyer, Alfred Wegener Institute, Germany

*Correspondence:

Tsukasa Gotow, Laboratory for Neuroanatomy, Department of

Neurology, Graduate School of Medical and Dental Sciences, Kagoshima University, 8-35-1 Sakuragaoka,

Kagoshima 890-8520, Japan.

e-mail: tsukasa@m.kufm.kagoshima-u. ac.jp
Simple photoreceptors, namely intrinsically light-sensitive neurons without microvilli and/or cilia, have long been known to exist in the central ganglia of crayfish, Aplysia, Onchidium, and Helix. These simple photoreceptors are not only first-order photosensory cells, but also second-order neurons (interneurons), relaying several kinds of sensory synaptic inputs. Another important issue is that the photoresponses of these simple photoreceptors show very slow kinetics and little adaptation. These characteristics suggest that the simple photoreceptors of the Onchidium have a function in non-image-forming vision, different from classical eye photoreceptors used for cording dynamic images of vision. The cited literature provides evidence that the depolarizing and hyperpolarizing photoresponses of simple photoreceptors play a role in the long-lasting potentiation of synaptic transmission of excitatory and inhibitory sensory inputs, and as well as in the potentiation and the suppression of the subsequent behavioral outputs. In short, we suggest that simple photoreceptors operate in the general potentiation of synaptic transmission and subsequent motor output; i.e., they perform a new photosensory function.

Keywords: molluscan simple photoreceptors, photoresponsive neurons similar to ipRGC, phototransduction, photosensory synaptic potentiation, potentiated sensory inputs

\section{INTRODUCTION}

It has been known since the 1930s that photoresponsive neurons that are intrinsically sensitive to light exist in the central ganglia of some invertebrates besides the photoreceptor cells (photoreceptors) in classical bilateral eyes. For instance, there are photoresponsive neurons in the sixth abdominal ganglion of the crayfish (Kennedy, 1963) and the visceral (abdominal) or pleuro-parietal ganglia of the sea slugs Aplysia (Arvanitaki and Chalazonitis, 1961; Brown and Brown, 1973) and Onchidium verruculatum (Hisano et al., 1972; Gotow, 1989).

We refer to these neurons as simple photoreceptors, in view of their lack of any specialized structures, such as microvilli and/or cilia, that are characteristic of classical eye photoreceptors (see review, Gotow and Nishi, 2008). In addition, it is known that these simple photoreceptors are not only first-order photosensory cells, but are also second-order neurons (interneurons), relaying several kinds of sensory inputs (Kennedy, 1963; Frazier et al., 1967; Gotow, 1975).

Recently, similar simple photoreceptors, the intrinsically photosensitive retinal ganglion cells (ipRGC), were discovered in mammalian retinas (Berson et al., 2002; Hattar et al., 2002), and their relevance will be discussed later.

A considerable amount of information has been obtained about the phototransduction mechanisms underlying the firstorder photosensory responses of invertebrates, especially that of the simple photoreceptors of Onchidium (for review, Gotow and Nishi, 2008). However, little has yet been established about how their simple photoreceptor functions as second-order neurons (interneurons) in vivo.
This review examines the non-image-forming visual functions of simple photoreceptors acting as second-order neurons. In addition, we survey the profiles of the cell membrane channels that mediate related receptor potentials and the phototransduction mechanisms of the simple photoreceptors studied to date.

\section{CHARACTERISTICS OF SIMPLE PHOTORECEPTORS (PHOTORESPONSIVE NEURONS)}

Several simple photoreceptors (photoresponsive neurons) have been identified on the dorsal aspect of the central ganglia of Onchidium verruculatum, a species closely related to Aplysia (Hisano et al., 1972; Gotow, 1989; Nishi and Gotow, 1998). Of these simple photoreceptors, which were designated Ep-2, Ep-3, Es-1, A-P-1, Ip-1, and Ip-2, A-P- 1 and Es- 1 respond to light with a depolarizing receptor potential, which is associated with a decrease in membrane $\mathrm{K}^{+}$ conductance (Gotow, 1989; Nishi and Gotow, 1992); whereas, Ip-1 and Ip-2 are hyperpolarized by light, owing to an increase in membrane $\mathrm{K}^{+}$conductance (Nishi and Gotow, 1998). These intrinsic photoresponses persist even when synaptic transmission is blocked either chemically or by ligation of the axo-somatic junction. Ep-2 and Ep-3 are depolarized by light, but their depolarizing mechanism is still unknown. However, we have evidence that Ep-2 and Ep-3 are also depolarized by a similar mechanism to that of A-P-1 and Es-1. Both of these depolarizing and hyperpolarizing photoresponses take 20 to $30 \mathrm{~s}$ to reach their peak after a latency of 300 to $500 \mathrm{~ms}$ following a brief light stimulus and then decline gradually. This contrasts with the fast and adaptive photoresponses of a few milliseconds to a few seconds in classical eye photoreceptors, e.g. the proximal and distal cells of Pecten (McReynolds and Gorman, 
1970) and the stalk eyes of Onchidium (Katagiri et al., 1985). When eliciting electrophysiological responses, the action spectrum peaked at about $490 \mathrm{~nm}$ in A-P-1 (Gotow, 1989) and at about $580 \mathrm{~nm}$ in Es-1 (Nishi and Gotow, 1992), while those in Ip-1 and Ip-2 both peaked at about $510 \mathrm{~nm}$, suggesting that each of their photoresponses is mediated by a single photopigment. Unfortunately, this photopigment has not yet been found in the Onchidium simple photoreceptors, although the presence of a rhodopsin-like protein was suggested in the Aplysia photoresponsive neuron R2 (Robles et al., 1986). On the other hand, the Onchidium photoresponsive neurons as well as the above mentioned Aplysia neurons are indistinguishable from the other light insensitive neurons in the ganglion by visual inspection. Electron microscopic observation showed that these photoresponsive neurons lack morphologically specialized structures, such as microvilli or cilia, that are characteristic of classical eye photoreceptors (Frazier et al., 1967; Kubozono, 1988). Thus, we consider that these photoresponsive neurons should be termed "simple photoreceptors". In addition, the simple photoreceptors in the Onchidium and Aplysia ganglia are not only first-order photosensory cells, but are also second-order neurons (interneurons), relaying several kinds of sensory inputs (Frazier et al., 1967; Gotow, 1975; Nishi et al., 2006), similar to those in the crayfish ganglion.

Recently, similar simple photoreceptors without microvilli or cilia, the ipRGC, were discovered in mammalian rat and mouse retinas (Berson et al., 2002; Hattar et al., 2002). Their studies suggested that their visual pigment may be melanopsin, an invertebrate-like photopigment, which was first identified in frog skin by Provencio et al. (1998). The latest studies have provided compelling evidence that melanopsin is the photopigment of the ipRGC (Melyan et al., 2005; Panda et al., 2005; Qiu et al., 2005). According to Berson (2003) and Do et al. (2009), the ipRGC show a delayed, slow, and lasting depolarizing photoresponse (in the order of a few seconds to tens of seconds) following a suitably brief light stimulation, which is different from the fast and adaptive hyperpolarizing response (in the order of a few milliseconds to tens of milliseconds) seen in cones and rods. In addition to being primary photosensory cells, the ipRGC are also second-order interneurons, relaying photic inputs from rods/cones to the brain. These characteristics of a lack of morphologically specialized structures, morphological arrangement as second-order neurons, and slow photoresponse kinetics in the ipRGC parallel those of the invertebrate Onchidium simple photoreceptors mentioned above. This reminds us that the mammalian ipRGC seem to be homologous to the invertebrate Onchidium simple photoreceptors.

\section{PHOTOTRANSDUCTION MECHANISM}

The primary function of simple photoreceptors and eye photoreceptors is to convert light energy into an electrical response, namely the receptor potential that is generated by light-dependent conductance or channels. Little work has been done on the ionic conductance mechanism in the excitatory, depolarizing photoresponses of the simple photoreceptors in crayfish (Kennedy, 1963) and Aplysia (Arvanitaki and Chalazonitis, 1961) ganglia.

A single-channel analysis showed that the depolarizing photoresponses of A-P-1 and Es-1 cells are produced by the closing of one class of $\mathrm{K}^{+}$-selective channel (Gotow, 1989; Gotow et al., 1994; Gotow and Nishi, 2002). Later, it was reported that the Helix simple photoreceptors also respond to light with membrane depolarization, due to a decrease in $\mathrm{K}^{+}$conductance (Pasic and Kartelija, 1995). On the other hand, we demonstrated that the hyperpolarizing receptor potential of Ip-2 and Ip-1 cells results from the opening of the same $\mathrm{K}^{+}$-selective channel that induces hyperpolarizing receptor potentials in A-P-1 and Es-1 cells (Nishi and Gotow, 1998; Gotow and Nishi, 2002).

It is thought that the hyperpolarizing photoresponses of most vertebrate eye photoreceptors (rods and cones) are produced by the closing of non-selective cation channels or by a decrease in membrane cation conductance (Tomita, 1972; Owen, 1986; Matthews and Watanabe, 1987). Only one known exception has been found, the lizard parietal eye photoreceptors, which responds to light with depolarization resulting from the opening of non-selective cation channels similar to those of the above mentioned vertebrate eye photoreceptors (Solessio and Engbretson, 1993). Except for this parietal photoreceptor, the above mentioned mechanism contrasts with that in the eye photoreceptors studied to date in invertebrates, which are present in most members of the animal kingdom; i.e., a depolarizing or a hyperpolarizing photoresponse is produced by the opening of membrane cation channels or by an increase in membrane cation conductance (Fuortes, 1963; Washizu, 1964; Brown et al., 1970; Pinto and Brown, 1977; Bacigalupo and Lisman, 1983; Nagy and Stieve, 1990; Nasi and Gomez, 1992; Gomez and Nasi, 1994). Thus, the simple photoreceptors of Onchidium, A-P-1 and Es-1, are the first invertebrate eye or simple photoreceptor in which it has been demonstrated that their photoresponses result from the "closing of channels" or "decreases in conductance".

The cGMP-gated channels in the vertebrate photoreceptors that close in light are non-selective cation channels permeable to $\mathrm{Na}^{+}$, $\mathrm{K}^{+}$, and $\mathrm{Ca}^{2+}$ (for review, Finn et al., 1996). However, the cGMPgated channels in the simple photoreceptors of Onchidium that close and open in the light are predominantly $\mathrm{K}^{+}$selective under physiological ionic conditions such as of $\mathrm{K}^{+}, \mathrm{Na}^{+}, \mathrm{Ca}^{2+}, \mathrm{Mg}^{2+}$ and $\mathrm{Cl}^{-}$; i.e., the contributions of these ions except for $\mathrm{K}^{+}$to these channels is negligible (Gotow, 1989; Gotow et al., 1994; Nishi and Gotow, 1998; Gotow and Nishi, 2002). Interestingly, we have found that the $\mathrm{K}^{+}$-selective channels of the simple photoreceptors of Onchidium can be specifically blocked by the external addition of $0.1-0.2 \mathrm{mM}$ 4-aminopyridine (4-AP) or 0.2-0.4 mM L-cis-diltiazem (L-DIL) (Gotow et al., 1997; Nishi and Gotow, 1998). L-DIL, a stereoisomer of the D-type $\mathrm{Ca}^{2+}$ channel blocker, specifically blocks the nonselective cation channels in vertebrate rod and cone cells (Stern et al., 1986; Rispoli and Menini, 1988; Haynes, 1992; McLatchie and Matthews, 1994) and light -dependent $\mathrm{K}^{+}$conductance in Pecten hyperpolarizing eye (ciliary) cells (Gomez and Nasi, 1997). 4-AP is another well-known blocker of $\mathrm{K}^{+}$channels, e.g., the $\mathrm{I}_{\mathrm{A}}$ or $\mathrm{K}_{\mathrm{A}}$ channels, which are transiently activated in the subthreshold range of membrane potentials (Hagiwara et al., 1961; Hermann and Gorman, 1981; Hille, 1992).

As described above, the simple photoreceptors A-P-1 and Es-1, which are depolarized by light, seem to be homologous to the vertebrate eye photoreceptors in the sense that both of their cGMP-gated channels are closed by light, although the polarity of their receptor potentials is reversed. This homology prompted us to examine whether the phototransduction cGMP cascade model used for vertebrate rod and cone photoreceptors (Fesenko et al., 
1985, for review, Finn et al., 1996; Kaupp and Seifert, 2002) can be applied to that of A-P-1 or Es-1. According to the cGMP cascade model, cGMP acts as a second messenger that opens cGMP-gated non-selective cation channels, allowing the channels to close when light activates PDE (phosphodiesterase) in order to reduce internal cGMP levels through a Gt-type G-protein (transducin), thereby leading to a hyperpolarizing response (Table 1). As in the above mentioned vertebrate cGMP cascade, we also concluded that cGMP acts as a second messenger that opens the cGMP-gated $\mathrm{K}^{+}$-selective channels of the simple photoreceptors A-P-1 and Es-1, allowing the channels to close when light activates PDE (phosphodiesterase) in order to reduce cGMP levels through a Gt-type G-protein $(\mathrm{Gt})$, thereby leading to depolarization (Gotow et al., 1994; Gotow and Nishi, 2002), as shown in Table 1.

On the other hand, we found that the hyperpolarizing photoresponses of other types of simple photoreceptor, Ip-2 and Ip-1 cells, are produced by the opening of the same type of channel that is closed in A-P-1 and Es-1 cells (Gotow and Nishi, 2002). Thus, Gotow and Nishi (2007) have proposed a new type of cGMP cascade model in which Ip-2 and Ip-1 cells are hyperpolarized when light activates GC (guanylate cyclase) through a Go-type G-protein (Go), leading to an increase in the level of the second messenger cGMP, thereby producing the opening of the same channels opened in AP-1 and Es- 1 cells (see also Table 1). A similar phototransduction model has also been suggested to operate in a different system, the scallop ciliary eye photoreceptor (Kojima et al., 1997; Gomez and Nasi, 1995, 2000). Unfortunately, no molecular identification of the visual pigment or G-protein involved in phototransduction has yet been undertaken in the simple photoreceptors of Onchidium.

In the related Aplysia simple photoreceptor R2, it has long been known that when illuminated, $\mathrm{R} 2$ hyperpolarizes due to an increase in membrane $\mathrm{K}^{+}$conductance and that this light-dependent $\mathrm{K}^{+}$ conductance is activated by a rise in the intracellular levels of $\mathrm{Ca}^{2+}$; i.e., the light-dependent $\mathrm{K}^{+}$conductance is equivalent to this $\mathrm{Ca}^{2+}$ activated $\mathrm{K}^{+}$conductance (Meech, 1972; Brown and Brown, 1973; Brown et al., 1977). However, no single-channel analysis of the hyperpolarizing photoresponse in $\mathrm{R} 2$ has been undertaken.

Furthermore, a considerable amount of information has been obtained about the photochemistry of melanopsin in ipRGC (for review, He et al., 2003; Peirson and Foster, 2006). For example, it has been suggested that melanopsin activates phospholipase $C$ through the Gq G-protein, as in Drosophila rhabdomeric photoreceptors (Raghu et al., 2000; for review, Hardie, 2003). However, the cell membrane channels and their channel-gating mechanism that mediate the photoreceptor potential of ipRGC have not yet been identified, so the phototransduction mechanism that couples melanopsin to its photoreceptor potential remains unknown (for review, Berson, 2007).

\section{PHOTOSENSITIVITY OF SIMPLE PHOTORECEPTORS IN VIVO}

The simple photoreceptors in the central ganglia, which are well covered by the animal's body wall, seem to be unsuitable as a classical photosensory system, but these simple photoreceptors may have adapted to serve as a new photosensory modality; i.e., nonimage-forming vision.

The amount of light energy transmitted through the Onchidium body wall, which is composed of the mantle and foot, was measured and compared with the energy required for a minimally detectable photoresponse in their simple photoreceptors. The spectral energy of incident sunlight was also measured in the centre of Kagoshima, which corresponds to that at Sakurajima beach, the home of the Onchidium tested.

These analyses supported the assertion that the transmittance of daylight through the animal's body wall is high enough to stimulate the simple photoreceptors of the Onchidium in vivo (Gotow et al.,

Table 1 | Phototransduction cGMP cascade models of simple photoreceptors.

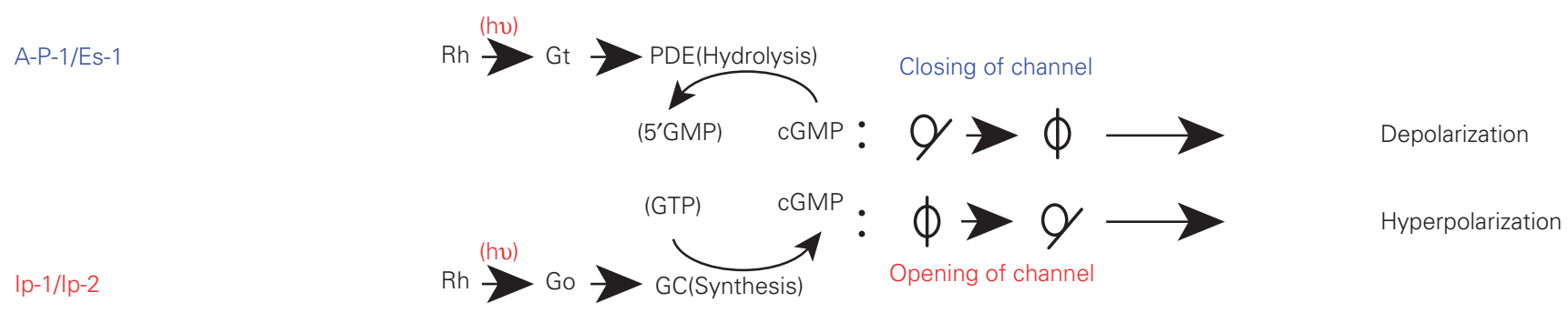

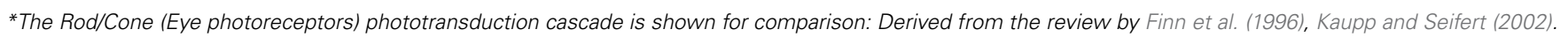
A-P-1/Es-1: Depolarizing A-P-1 and Es-1 cells. Ip-1/Ip-2: Hyperpolarizing Ip-1 and Ip-2 cells. Rh: Visual pigments, PDE: Phosphodiesterase, GC: Guanylate cyclase. 
2005). Brown et al. (1977) have also reported that the amount of light energy required to stimulate the simple photoreceptors of the Aplysia in vivo can be provided by the transmittance through the animal's body wall.

Non-image-forming visual function:

1. Depolarizing Ep-2, Ep-3, and Es-1 cells

2. Hyperpolarizing Ip-1 and Ip-2 cells

Little has been definitively established about the functional significance of simple photoreceptors. In spite of a concerted effort to elucidate the functions of the 6th abdominal ganglion simple photoreceptors of crayfish, many questions remain (for review, Wilkens, 1988). It has only been postulated that the simple photoreceptors of crayfish operate in the general regulation of synaptic transmission (Kennedy, 1963; Wilkens and Larimer, 1972; Pei et al., 1996). The function of the simple photoreceptors of Aplysia (Arvanitaki and Chalazonitis, 1961; Brown and Brown, 1973) is also unknown. However, it has been reported that Aplysia demonstrate light-entrained behavior in the absence of bilateral eyes and that simple photoreceptors such as R2 may be involved in such behavior (Block and Lickey, 1973; Block et al., 1974).

Onchidium are intertidal and amphibian mollusks. Thus, they use gill-trees at high tide, but at low tide they begin to use their lung (pulmonary sac) for respiration and crawl over the rocks on the exposed seashore in order to obtain food or to reproduce. Occasionally, Onchidium slip and turn over, while rock-crawling. In such cases, these animals pick themselves up through a chain of behavioral responses, such as the mantle-levating reflex (Gotow et al., 1973). This mantle-levating reflex is also reproducibly triggered by tactile stimulation of the animal's dorsal surface, the mantle.

On the other hand, Gotow (1975) and Gotow et al. (1973) have shown that the first-order depolarizing simple photoreceptors Ep-2, Ep-3, and Es-1 are not only second-order neurons relaying tactile sensory inputs from the mantle through the specified peripheral nerves, but are also motoneurons innervating the mantle and foot (mesopodium) so the combined spike activity evoked by tactile synaptic transmission in these three cell types results in a levation movement of the mantle equivalent to the mantle-levating reflex (Figure 1A). They have also shown that all excitatory synaptic transmissions and potentials induced by tactile sensory inputs in these cells are potentiated during light illumination, even when the preceding light stimulus is subthreshold. Thus, it has been suggested that the depolarizing photoresponses of Ep-2, Ep-3, and Es-1 cells play a role in the potentiation of the excitatory synaptic transmission and potentials related tactile sensory inputs and the subsequent mantle-levating reflex (Gotow et al., 1973) and so may be involved in a new photosensory modality, non-image-forming vision.

At low tide, the amphibian mollusks Onchidium open their pneumostome, the orifice of their pulmonary sac, in order to begin aero-respiration, although they close the pneumostome at high tide. The opening of the pneumostome; i.e., an aero- breathing behavior, can also be reproducibly triggered by removal of the surrounding seawater from the animal's body surface such as the mantle, pneumostome, etc. or by moving the animal from underwater to air.
A Depolarizing Ep-2, Ep-3 and Es-1 Excitatory tactile inputs

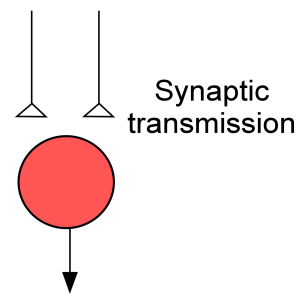

Spike discharge evoked

by tactile stimulation

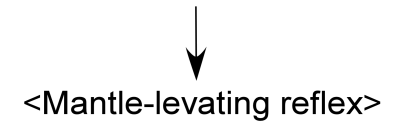

B Hyperpolarizing Ip-1 and Ip-2

Inhibitory pressure inputs

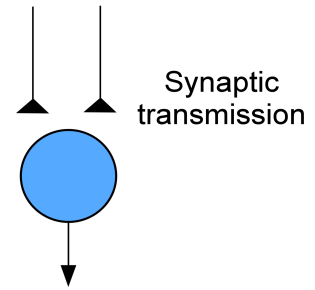

Endogeneously occuring spike discharge

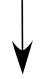

<Aero-breathing behavior>

Long-lasting potentiation of excitatory and inhibitory

synaptic transmissions during the light illumination

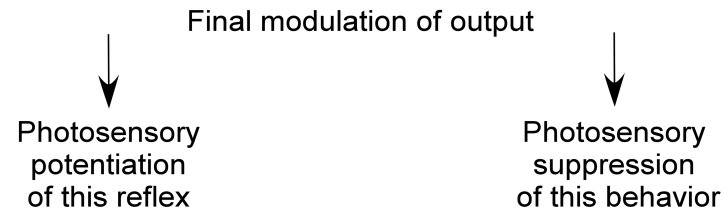

FIGURE 1 |Chart showing a new photosensory function of Onchidium simple photoreceptors, (A) depolarizing and (B) hyperpolarizing cells. See text for details. 
On the other hand, Nishi et al. (2006) and Gotow and Nishi (2008) have found that the first-order hyperpolarizing simple photoreceptors Ip-1 and Ip-2 are not only second-order neurons that receive inhibitory presynaptic inputs, such as water pressure and/or tactile signals arising from the animal's body surface, but are also interneurons (motor-like neurons) involved in aero-breathing behavior. Thus, they suggested that at low tide these cells are released from inhibitory sensory synaptic inputs such as water pressure and/or touch and begin to produce endogenous spike discharges, thereby leading to opening of the pneumostome (Figure 1B).

An attempt to examine the effects of light on the hyperpolarizing Ip-1 and Ip-2 cells showed that inhibitory synaptic transmissions and potentials related to pressure and/or tactile sensory inputs in these cells are potentiated during light illumination, even if the preceding light stimulus is subthreshold. This result suggested that the hyperpolarizing photoresponse of Ip-1 and Ip-2 cells operates in the potentiation of inhibitory synaptic transmission as well as in the suppression of subsequent aero-breathing behavior (Nishi et al., 2006; Gotow and Nishi, 2008) and so may also be involved in the above mentioned new photosensory modality.

The above mentioned potentiation of excitatory and inhibitory synaptic transmission by simple photoreceptors occurred even when their photoresponses were subthreshold, demonstrating true "potentiation" rather than only "summation"; i.e., the sum of synaptic potentials and photoreceptor potentials. Furthermore, we refer to this potentiation as "long-lasting potentiation". As the photoresponses of simple photoreceptors can last for hours and even days, they are effective during most daylight hours.

\section{REFERENCES}

Arvanitaki, A., and Chalazonitis, N. (1961). Excitatory and inhibitory processes initiated by light and infrared radiations in single identifiable nerve cells (giant ganglion cells of Aplysia). In Nervous inhibition, E. Florey ed. (Oxford, Pergamon), pp. 194-231.

Bacigalupo, J., and Lisman, J. E. (1983). Single-channel currents activated by light in Limulus ventral photoreceptors. Nature 304, 268-270.

Berson, D. M. (2003). Strange vision: ganglion cells as circadian photoreceptors. Trends Neurosci. 26, 314-320.

Berson, D. M. (2007). Phototransduction in ganglion-cell photoreceptors. Pflugers Arch. 454, 849-855.

Berson, D. M., Dunn, F. A., and Takao, M. (2002). Phototransduction by retinal ganglion cells that set the circadian clock. Science 295, 1070-1073.

Block, G. D., Hudson, D. J., and Lickey, M. E. (1974). Extraocular photoreceptors can entrain the circadian oscillator in the eye of Aplysia. J. comp. Physiol. 89, 237-249.

Block, G. D., and Lickey, M. E. (1973). Extraocular photoreceptors and oscillators can control the circadian rhythm

On the other hand, it has been reported that ipRGC operate in non-visual functions such as the pupillary light reflex and circadian photoentrainment (Panda et al., 2002, 2003; Ruby et al., 2002; Hattar et al., 2003; Lucas et al., 2003). However, nothing is known about their light-sensing functions as interneurons. Most recently, Do et al. (2009) reported that the ipRGC in transgenic mice modulated rod/cone response and synaptic signal transmission from amacrine and bipolar cells, etc. to the brain.

\section{CONCLUSION}

Simple photoreceptors similar to those of Onchidium have been known to exist in the central ganglion of crayfish, Aplysia, and Helix since the 1930s. Recently, similar simple photoreceptors, ipRGC, have been discovered in the ganglion cells of mammalian retinas. It was suggested that the simple photoreceptors of Onchidium as well as ipRGC function as a new sensory modality, non-image-forming vision, which is different from the image-forming vision of classical eye photoreceptors. As non-image-forming functions of ipRGC, it is known that they contribute to pupillary light reflex and circadian clocks. However, their light-sensing function as interneurons has not been ascertained. An Onchidium study showed that simple photoreceptors (Ep-2, Ep-3, A-P-1, Es-1, Ip-1, and Ip-2) play roles in the long-lasting potentiation of synaptic transmission of excitatory and inhibitory sensory inputs as well as in the potentiation and suppression of the subsequent behavioral responses. Figure 1 shows a chart that explains these non-image-forming functions of simple photoreceptors. Interestingly, it seems that both simple photoreceptors and classical eye photoreceptors use the same phototransduction and channel-gating mechanisms (see Table1), in spite of the great difference in the functions of these two types of photoreceptors.

(1967). Morphological and functional properties of identified neurons in the abdominal ganglion of Aplysia californica. J. Neurophysiol. 30, 1288-1351.

Fuortes, M. G. F. (1963). Visual responses in the eye of the dragonfly. Science 142, 69-70.

Gomez, M., and Nasi, E. (1994). The light-sensitive conductance of hyperpolarizing invertebrate photoreceptors: a patch-clamp study. J. Gen. Physiol. 103, 939-956.

Gomez,M., and Nasi,E. (1995). Activation of light-dependent $\mathrm{K}^{+}$channels in ciliary invertebrate photoreceptors involves cGMP but not the $\mathrm{IP}^{3} / \mathrm{Ca}^{2}+$ cascade. Neuron 15, 607-618.

Gomez, M., and Nasi, E. (1997). Antagonists of the cGMP-gated conductance of vertebrate rods block the photocurrent in scallop ciliary photoreceptors. J. Physiol. 500, 367-378.

Gomez, M., and Nasi, E. (2000). Light transduction in invertebrate hyperpolarizing photoreceptors: possible involvement of a Go-regulated guanylate cyclase. J. Neurosci. 20 5254-5263.

Gotow, T. (1975). Morphology and function of the photoexcitable neurones in the central ganglion of Onchidium verruculatum. J. Comp. Physiol. 99, 139-152.

Gotow, T. (1989). Photoresponses of an extraocular photoreceptor associated with a decrease in membrane conductance in an opisthobranch mollusc. Brain Res. 479, 120-129.

Gotow, T., and Nishi, T. (2002). Lightdependent $\mathrm{K}^{+}$channels in the mollusc Onchidium simple photoreceptors are opened by cGMP. J. Gen. Physiol. 120, 581-597.

Gotow, T., and Nishi, T. (2007). Involvement of a Go-type G-protein coupled to guanylate cyclase in the phototransduction cGMP cascade of molluscan simple photoreceptors. Brain Res. 1144, 42-51.

Gotow, T., and Nishi, T. (2008). Simple photoreceptors in some invertebrates: physiological properties of a new photosensory modality. Brain Res. 1225, 3-16.

Gotow, T., Nishi, T., and Kijima, H. (1994). Single $\mathrm{K}^{+}$channels closed by light and opened by cyclic GMP in molluscan extra-ocular photoreceptor cells. Brain Res. 662, 268-272.

Frazier, W. T., Kandel, E. R., Kuppermann, I., Waziri, R., and Coggeshall, R. E.
Gotow, T., Nishi, T., and Murakami, M. (1997). 4-Aminopyridine and 
L-cis-diltiazem block the cGMP-activated $\mathrm{K}^{+}$channels closed by light in the molluscan extra-ocular photoreceptors. Brain Res. 745, 303-308.

Gotow, T., Shimotsu, K., and Nishi, T. (2005). Non-image forming function of the extraocular photoreceptors in the ganglion of the sea slug Onchidium. Brain, vision, and artificial intelligence. In Proceedings of First International Symposium, M. D. Gregorio, V. D. Maio, M. Frucci, and C. Musio, eds (Berlin, Springer), pp. 136-145.

Gotow, T., Tateda, H., and Kuwabara, M. (1973). The function of photoexcitive neurones in the central ganglia for behavioral activity of the marine mollusc Onchidium verruculatum. J. comp. Physiol. 83, 361-376.

Hagiwara, S., Kusano, K., and Saito, N. (1961). Membrane changes of Onchidium nervecell in potassium-rich media. J. Physiol. 155, 470-489.

Hardie, R. C. (2003). Regulation of TRP channels via lipid second messengers. Annu. Rev. Physiol. 65, 735-759.

Hattar, S., Liao, H.-W., Takao, M., Berson, D. M., and Yau, K. W. (2002). Melanopsin-containing retinal ganglion cells: architecture, projections, and intrinsic photosensitivity. Science 295, 1065-1070.

Hattar, S., Lucas, R. J., Mrosovsky, N., Thompson, S., Douglas, R. H., Hankins, M. W., Lem, J., Biel, M., Hofmann, F., Foster, R. G., and Yau, K. W. (2003). Melanopsin and rodcone photoreceptive systems account for all major accessory visual functions in mice. Nature 424, 76-81.

Haynes, L. W. (1992). Block of the cyclic GMP-gated channel of vertebrate rod and cone photoreceptors by L-cis-diltiazem. J. Gen. Physiol. 100, 783-801.

He, S., Dong, W., Deng, Q., Weng, S., and Sun, W. (2003). Seeing more clearly: Recent advances in understanding retinal circuitry. Science 302, 408-411.

Hermann,A., and Gorman, A. L. F. (1981). Effects of 4-aminopyridine on potassium currents in a molluscan neurons. J. Gen. Physiol. 78, 63-86.

Hille, B. (1992). Ionic Channels of Excitable Membranes, 2nd Edn. Sunderland, MA, Sinauer.

Hisano, N., Tateda, H., and Kuwabara, M. (1972). A Photosensitive neurones in the marine pulmonate mollusc Onchidium verruculatum. J. Exp. Biol. 57, 651-660.

Katagiri, Y., Katagiri, N., and Fujimoto, K. (1985). Morphological and electrophysiological studies of a multiple photoreceptive system in a marine gastropod, Onchidium. Neurosci. Res. Suppl. 2, S1-S15.
Kaupp, U. B., and Seifert, R. (2002). Cyclic nucleotide-gated ion channels. Physiol Rev. 82, 769-824.

Kennedy, D. (1963). Physiology of photoreceptor neurons in the abdominal nerve cord of the crayfish. J. Gen. Physiol. 46, 551-572.

Kojima, D., Terakita, A., Ishikawa, T. Tsukahara, Y., Maeda, A., and Shichida, Y. (1997). A novel Go-mediated phototransduction cascade in scallop visual cells. J. Biol. Chem. 272, 22979-22982.

Kubozono, T. (1988). A study on an extraocular photoreceptor in the central ganglia of the marine gastropod mollusc, Onchidium verruculatum. (in Japanese). Med. J. Kagoshima Univ. 40, 161-178.

Lucas, R. J., Hattar, S., Takao, M., Berson, D. M., Foster, R. G., and Yau, K. W. (2003). Diminished pupillary light reflex at high irradiances in melanopsin-knockout mice. Science 299, 245-247.

Matthews, G., and Watanabe, S. (1987). Properties of ion channels closed by light and opened by guanosine $3^{\prime}, 5^{\prime}$ cyclic monophosphate in toad retinal rods. J. Physiol. 389, 691-715.

McLatchie, L. M., and Matthews, H. R. (1994). The effect of $\mathrm{pH}$ on the block by L-cis-diltiazem and amiloride of the cyclic GMP-activated conductance of salamander rods. Proc. R. Soc. Lond., B, Biol. Sci. 255, 231-236.

McReynolds, J. S., and Gorman, A. L. (1970). Photoreceptor potentials of opposite polarity in the eye of the scallop, Pecten irradians. J. Gen. Physiol. 56, 376-391.

Meech, R.W. (1972). Intracellular calcium injection causes increased potassium conductance in Aplysia nerve cells. Comp. Biochem. Physiol., A 42, 493-499.

Melyan,Z., Tarttelin, E. E., Bellingham, R. J., Lucas, M., and Hankins, W. (2005). Addition of human melanopsin renders mammalian cells photoresponsive. Nature 433, 741-745.

Nagy, K. and Stieve, H. (1990). Lightactivated single channel currents in Limulus ventral nerve photoreceptors. Euro. Biophys. J. 18, 220-224.

Nasi, E., and Gomez, M. (1992). Lightactivated ion channels in solitary photoreceptors from the eye of the scallop Pecten irradians. J. Gen. Physiol. 99, 747-769.

Nishi, T., and Gotow, T. (1992). A neural mechanism for processing colour information in molluscan extraocular photoreceptors. J. Exp. Biol. 168, 77-91.

Nishi, T., and Gotow, T. (1998). Lightincreased cGMP and $\mathrm{K}^{+}$conductance in the hyperpolarizing receptor potential of Onchidium extra-ocular photoreceptors. Brain Res. 809, 325-336.
Nishi, T., Gotow, T., and Nakagawa, S. (2006). Non-image-forming visual function of the simple photoreceptors in the sea slug Onchidium ganglion. Neurosci. Res. 55, S176.

Owen, W. G. (1986). The light-induced conductance change in the vertebrate rod. In The Molecular Mechanism of Photoreception, H. Stieve, ed. (Berlin, Springer-Verlag) pp. 171-187.

Panda, S., Nayak, K. S., Campo, B., Walker, J. R., Hogenesch, J. B., and Jegla, T. (2005). Illumination of the melanopsin signaling pathway. Science 307 , 600-604.

Panda, S., Provencio, I., Tu, D. C., Pires, S. S., Rollag, M. D., Castrucci, A. M., Pletcher, M. T., Sato, T. K., Wiltshire, T., Steve, A., Kay, S. A., Van Gelder, R. N., and Hogenesch, J. B. (2003). Melanopsin is required for nonimage-forming photic responses in blind mice. Science 301, 525-527.

Panda, S., Sato, T. K., Castrucci, A. M., Rollag, M. D., DeGrip, W. J., Hogenesch, J. B., Provencio, I., and Kay, S.A. (2002). Melanopsin (Opn4) requirement for normal light-induced circadian phase shifting. Science 298, 2213-2216.

Pasic, M., and Kartelija, G. (1995). The reaction of Helix photosensitive neurons to light and cyclic GMP. Neuroscience 69, 557-565.

Pei, X., Wilkens, L. A., and Moss, F. (1996). Light enhances hydrodynamic signaling in the multimodal caudal photoreceptor interneurons of the crayfish. J. Neurophysiol. 76, 3002-3011.

Peirson, S., and Foster, R. G. (2006) Melanopsin: another way of signaling light. Neuron 49, 331-339.

Pinto, L. H. and Brown, J. E. (1977). Intracellular recordings from photoreceptors of the squid (Loligo pealii). J. Comp. Physiol. A. 122 , 241-250.

Provencio, I., Jiang, G., De Grip, W. J., Hayes, W. P., and Rollag, M. D. (1998) Melanopsin: an opsin in melanophores, brain, and eye. Proc. Natl. Acad. Sci. U.S.A. 95, 340-345.

Qiu, X., Kumbalasiri, T., Carlson, S. M. Wong, K. Y., Krshna, V., Provencio, I., and Berson, D. M. (2005). Induction of photosensitivity by heterologous expression of melanopsin. Nature 433, 745-749.

Raghu, P., Usher, K., Jonas, S., Chyb, S., Polyanovsky, A., and Hardie, R. C. (2000). Constitutive activity of the light-sensitive channels TRP and TRPL in the Drosophila diacylglycerol kinase mutant, rdgA. Neuron 26, 169-179.

Rispoli, G., and Menini, A. (1988). The blocking effect of L-cis-diltiazem on the light-sensitive current of isolated rods of the tiger salamander. Eur. Biophys. J. 16, 65-71.

Robles, L. J., Breneman, J. W., Anderson, E. O., Nottoli, V. A., and Kegler, L. L. (1986). Immunocytochemical localization of a rhodopsin-like protein in the lipochondria in photosensitive neurons of Aplysia californica. Cell Tissue Res. 244, 115-120.

Ruby, N. F., Brennan, T. J., Xie, X., Cao, V., Franken, P., Heller, H. C., and O'Hara, B. F. (2002). Role of melanopsin in circadian responses to light. Science 298, 2211-2213.

Solessio, E., and Engbretson, G. A. (1993). Antagonistic chromatic mechanisms in photoreceptors of the parietal eye of lizards. Nature 364, 442-445.

Stern, J. H., Kaupp, U. B., and MacLeish, P. R. (1986). Control of the lightregulated current in rod photoreceptors by cyclic GMP, calcium, and L-cis-diltiazem. Proc. Natl. Acad. Sci. U.S.A. 83, 1163-1167.

Tomita, T. (1972). Light-induced potential and resistance changes in vertebrate photoreceptors. In Handbook of Sensory Physiology. VII/2, M. G. F. Fuortes, ed. (Berlin, Springer-Verlag), pp. 483-511.

Washizu, Y. (1964). Electrical activity of single retinula cells in the compound eye of the blowfly Calliphora erythrocephala Meig. Comp. Biochem. Physiol. 12, 369-387.

Wilkens, L. A. (1988). The crayfish caudal photoreceptor: advances and questions after the first half century. Comp. Biochem. Physiol. 91C, 61-68.

Wilkens, L. A., and Larimer, J. L. (1972). The CNS Photoreceptor of crayfish: morphology and synaptic activity. $J$. comp. Physiol. 80, 389-407.

Conflict of Interest Statement: The authors declare that the research was conducted in the absence of any commercial or financial relationships that could be construed as a potential conflict of interest.

Received: 27 August 2009; paper pending published: 24 September 2009; accepted: 24 November 2009; published online: 09 December 2009

Citation: Gotow $T$ and Nishi T (2009) A new photosensory function for simple photoreceptors, the intrinsically photoresponsive neurons of the sea slug Onchidium. Front. Cell. Neurosci. 3:18. doi: 10.3389/neuro.03.018.2009

Copyright (C) 2009 Gotow and Nishi. This is an open-access article subject to an exclusive license agreement between the authors and the Frontiers Research Foundation, which permits unrestricted use, distribution, and reproduction in any medium, provided the original authors and source are credited. 